\title{
Hed1 regulates Rad51-mediated recombination via a novel mechanism
}

\author{
Valeria Busygina, ${ }^{1}$ Michael G. Sehorn, ${ }^{1,4}$ Idina Y. Shi, ${ }^{1}$ Hideo Tsubouchi, ${ }^{2,3,6}$ G. Shirleen Roeder, ${ }^{2}$ \\ and Patrick Sung ${ }^{1,5}$ \\ ${ }^{1}$ Department of Molecular Biophysics and Biochemistry, Yale University School of Medicine, New Haven, Connecticut \\ 06520, USA; ${ }^{2}$ Department of Molecular, Cellular, and Developmental Biology, Howard Hughes Medical Institute, Yale \\ University, New Haven, Connecticut 06520, USA; ${ }^{3}$ Marie Curie Research Institute, The Chart, Oxted, Surrey RH8 0TL, \\ United Kingdom
}

\begin{abstract}
Two RecA orthologs, Rad51 and Dmc1, mediate homologous recombination in meiotic cells. During budding yeast meiosis, Hed1 coordinates the actions of Rad51 and Dmc1 by down-regulating Rad51 activity. It is thought that Hed1-dependent attenuation of Rad51 facilitates formation of crossovers that are necessary for the correct segregation of chromosomes at the first meiotic division. We purified Hed1 in order to elucidate its mechanism of action. Hed1 binds Rad51 with high affinity and specificity. We show that Hed1 does not adversely affect assembly of the Rad51 presynaptic filament, but it specifically prohibits interaction of Rad51 with Rad54, a Swi2/Snf2-like factor that is indispensable for Rad51-mediated recombination. In congruence with the biochemical results, Hed1 prevents the recruitment of Rad54 to a site-specific DNA double-strand break in vivo but has no effect on the recruitment of Rad51. These findings shed light on the function of Hed1 and, importantly, unveil a novel mechanism for the regulation of homologous recombination.
\end{abstract}

[Keywords: Regulation of meiotic recombination; interhomolog crossovers; Rad51 recombinase; double-strand break repair; homologous recombination]

Supplemental material is available at http://www.genesdev.org.

Received November 30, 2007; revised version accepted January 18, 2008.

DNA double-strand breaks (DSBs) are strong inducers of homologous recombination (HR) (Symington 2002). In meiosis, genome-wide DSBs introduced by the Spo11associated protein complex trigger recombination between homologous chromosomes (Keeney et al. 1997; Neale and Keeney 2006). Some of these recombination events lead to the formation of interhomolog crossovers that are crucial for linking the homologous chromosomes, to ensure their proper alignment on the spindle apparatus and faithful disjunction in the first meiotic division. As such, interhomolog crossover recombination is indispensable for the successful execution of meiosis (Keeney et al. 1997; Neale and Keeney 2006; Sheridan and Bishop 2006).

Two recombinases, Rad51 and Dmc1, mediate recombination reactions in eukaryotes. Dmcl is found specifically in meiotic cells, whereas Rad51 is present in both the vegetative and meiotic states. Both recombinases catalyze DNA joint formation within the context of the presynaptic filament, which comprises a helical polymer

\footnotetext{
${ }^{4}$ Present address: Department of Genetics and Biochemistry, Clemson University, Clemson, South Carolina 29634, USA Corresponding authors.

${ }^{5}$ E-MAIL patrick.sung@yale.edu; FAX (203) 785-6404.

${ }^{6}$ E-MAIL h.tsubouchi@mcri.ac.uk; FAX 44-1883-714-375.

Article is online at http://www.genesdev.org/cgi/doi/10.1101/gad.1638708.
}

of the recombinase assembled on ssDNA derived from the nucleolytic processing of DSBs (Neale and Keeney 2006; Sung and Klein 2006).

In Saccharomyces cerevisiae there appear to be two distinct meiotic recombination pathways, with one being dependent on Rad51 alone (referred to as the Rad51only pathway) and the other on both Rad51 and Dmc1 (called the Dmcl-dependent pathway) (Tsubouchi and Roeder 2003). While Rad51 alone is able to repair meiotic DSBs, it has been demonstrated that coordinated function of Rad51 and Dmc1 is required to achieve the meiosis-specific bias for interhomolog recombination (Sheridan and Bishop 2006).

The ability of the Rad51-only pathway to mediate efficient sister chromatid repair of meiotic DSBs suggests the existence of a mechanism by which meiotic cells down-regulate Rad51 activity, so as to allow the Dmc1dependent pathway to process enough of the Spo11-made DSBs to yield interhomolog crossovers. In this regard, Red1, Hop1, and Mek1, which are associated with the cores of meiotic chromosomes, facilitate interhomolog crossover formation by attenuating the Rad51-only recombination pathway (Schwacha and Kleckner 1997; Xu et al. 1997; Niu et al. 2005).

Interestingly, the screen for high-copy suppressors of a hypomorphic red1 mutant has led to the identification of 
a meiosis-specific gene, HED1 (high-copy suppressor of red1), that appears to provide a mechanistically distinct means for down-regulating the Rad51-only pathway (Tsubouchi and Roeder 2006). Notably, deletion of HED1 in the $d m c 1$ mutant relieves the attenuation of Rad51dependent recombination and restores both spore viability and DSB repair efficiency, an effect similar to Rad51 overexpression in $d m c 1 \Delta$ cells. Moreover, expression of Hed1 in vegetative cells inhibits Rad51-dependent gene conversion events but not Rad51-independent singlestrand annealing reactions. The available genetic data indicate that Hed1 acts directly on Rad51 to attenuate the Rad51-only pathway, so as to facilitate Dmc1-mediated interhomolog crossover formation (Tsubouchi and Roeder 2006). Here, we describe biochemical and biological experiments directed at elucidating the molecular mechanism by which Hed1 regulates Rad51. The results reveal an unprecedented means of HR regulation.

\section{Results}

\section{Purification of Hed1}

We cloned HED1 cDNA into two separate bacterial vectors for the expression of Hedl protein either as an $\mathrm{N}$ terminally GST- and C-terminally $(\mathrm{His})_{6}$-tagged species (referred to simply as GST-Hed1) or as a C-terminally $(\text { His })_{6}$-tagged species (referred to simply as Hed1). Both Hed1 species are soluble, and we were able to purify a significant amount of them to near homogeneity (Fig. 1A,B) by combining several chromatographic fractionation steps with affinity chromatography on either glu-

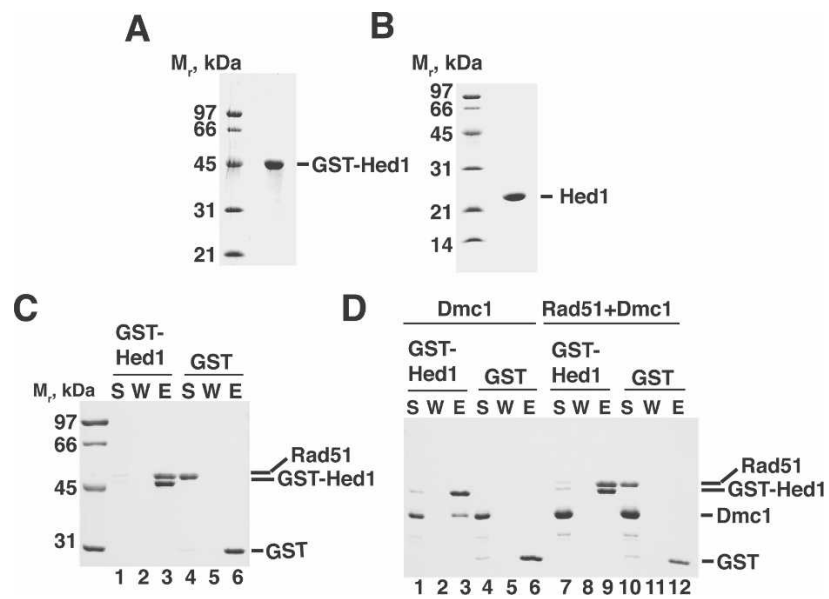

Figure 1. Hed1 interacts directly and specifically with Rad51. $(A, B)$ Purified GST-Hed 1 and Hed1, $5 \mu \mathrm{g}$ each, were analyzed by SDS-PAGE. $(C)$ GST-Hed $1(5 \mu \mathrm{g})$ or GST $(5 \mu \mathrm{g})$ was incubated with Rad51 (5 $\mu \mathrm{g})$, and protein complexes were captured on glutathione Sepharose beads, which were washed and treated with SDS to elute bound proteins. The supernatant (S) that contained unbound proteins, wash $(\mathrm{W})$, and SDS eluate $(\mathrm{E})$ were

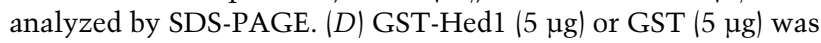
incubated with Dmc1 $(5 \mu \mathrm{g})$ or a mixture of Rad51 $(5 \mu \mathrm{g})$ and Dmc1 $(10 \mu \mathrm{g})$, and protein complexes were captured on glutathione Sepharose beads and analyzed as above. tathione or $\mathrm{Ni}^{2+}$-nitrilotriacetate agarose (see the Supplemental Material for details).

\section{Specific complex of Hed1 and Rad51}

Results from yeast two-hybrid and cytological analyses furnished evidence for a Hed1-Rad51 complex and suggested that Hed1 does not associate with Dmcl (Tsubouchi and Roeder 2006). We used an affinity pulldown assay with purified GST-Hed1, Rad51, and Dmc1 to test whether Hed1 interacts directly with the two recombinases. While GST-Hed1 bound Rad51 avidly, as evidenced by the fact that almost all of the Rad51 protein was found in the elution fraction with Hed1 (Fig. 1C, lane 3), it showed only weak affinity for Dmcl (Fig. 1D, lane 3). Moreover, when Rad51 and Dmcl were coincubated with a limiting quantity of GST-Hed1, only Rad51 became associated with GST-Hed1, even though Dmc1 was present in excess over Rad51 in the experiment (Fig. 1D, lane 9|. GST-Hed1 did not interact with the bacterial RecA protein at all (Supplemental Fig. S1A, lane 3). As expected, Rad51, Dmc1, and RecA did not bind GST (Fig. 1C [lane 6], 1D [lanes 6,12]; Supplemental Fig. S1A, lane 6). Overall, these results validate the yeast two-hybrid and cytological data (Tsubouchi and Roeder 2006) by providing biochemical evidence for a direct and highly specific interaction between Rad51 and Hed1.

\section{Hed1 does not impair Rad51 presynaptic filament assembly}

Since genetic evidence has implicated Hedl as an attenuator of Rad51 activity (Tsubouchi and Roeder 2006), we examined the influence that Hedl might have on the basic biochemical properties of Rad51. Rad51 possesses ssDNA-dependent ATPase activity (Sung 1994), so we tested whether Hed1 affects this attribute of Rad51. The results revealed that Hed1 has no ATPase activity, nor does it affect ATP hydrolysis by Rad51 (Fig. 2A). We next used an oligonucleotide-based homologous DNA pairing assay (Fig. 2B; San Filippo et al. 2006) to ask whether Hed1 has any effect on the recombinase function of Rad51. In this assay, ssDNA (150-mer) is incubated with Rad51 in the presence of ATP to assemble the presynaptic filament, which is then mixed with a radiolabeled duplex (40-mer), in which the radiolabeled strand is complementary to the middle portion of the ssDNA. The pairing between the DNA substrates and exchange of strands in the DNA joint molecule generate a radiolabeled partial duplex that harbors 150-mer and 40-mer strands and also free 40-mer ssDNA as products. Inclusion of Hed 1 in the recombination reaction not only did not inhibit the reaction, it also led to a slight stimulation at the higher Hed1 concentrations (Fig. 2C). Thus, Hed1 has no adverse effect on the assembly of the Rad51 presynaptic filament. We found that Hed1 is devoid of homologous DNA pairing activity (Fig. 2C, lane 2) and that, as expected, the reaction containing Rad51 and Hed1 remains ATP-dependent (data not shown). Control experi- 
A

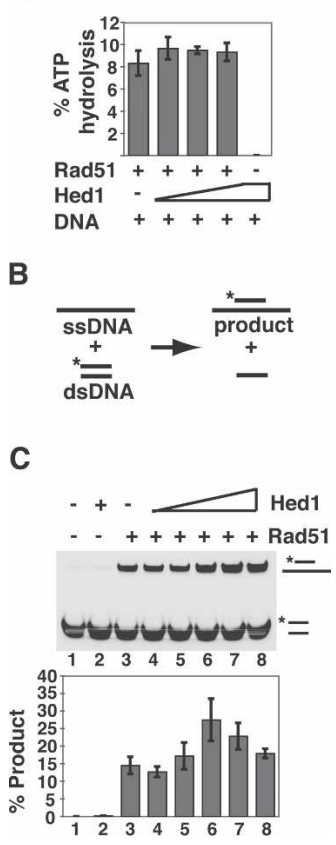

Figure 2. Hed1 does not inhibit Rad51-mediated reactions. (A) ATP hydrolysis by Rad51 with or without Hed1. Rad51 (3.45 $\mu \mathrm{M})$ was incubated with increasing amounts of Hed1 (1.3, 2.6, and $3.7 \mu \mathrm{M})$ and $\phi \mathrm{X}$ virion ssDNA $(90 \mu \mathrm{M}$ nucleotides $)$ in the appropriate buffer (see Materials and Methods). (B) Schematic for the oligonucleotide-based homologous DNA pairing assay (San Filippo et al. 2006). $\left({ }^{*}\right)^{32}$ P-labeled strand. $(C)$ Homologous DNA pairing by Rad51 with or without Hed1. Rad51 $(3.45 \mu \mathrm{M})$ was incubated with 150 -mer ssDNA (6 $\mu \mathrm{M}$ nucleotides) to form a filament. In the indicated lanes, Hed $1(0.5,1.3,2.6,3.7$, and 4.3 $\mu \mathrm{M})$ was added, followed by 40 -mer duplex (6 $\mu \mathrm{M}$ base pairs). (Lane 2) Hedl alone, at the highest concentration used in this assay, is devoid of homologous pairing activity. Error bars represent standard error of the mean (SEM).

ments showed that Hed1 does not affect RecA-mediated homologous DNA pairing and strand exchange (Supplemental Fig. S1B).

\section{Hed1 specifically interferes with Rad51-Rad54 interaction}

Optimal efficiency of Rad51-mediated recombination is reliant on several key ancillary factors (Symington 2002; Sung et al. 2003), Rad52 and Rad54 in particular. Rad52 functions in the assembly of the Rad51 presynaptic filament, whereas Rad54 enhances the ability of the presynaptic filament to catalyze DNA strand invasion (Heyer et al. 2006; Sung and Klein 2006). Functional synergy between Rad51 and Rad52 or Rad54 requires protein complex formation between Rad51 and these other HR factors (Shinohara and Ogawa 1998; Krejci et al. 2002; Raschle et al. 2004). We hypothesized that, since Hed1 does not directly affect the basic functional attributes of Rad51, it might interfere with Rad51's interaction with other HR factors. We used affinity pull-down assays with purified proteins to test this premise. We did not find any effect of Hed1 on Rad51-Rad52 complex formation (Supplemental Fig. S2, lanes 6,9). In contrast, we saw a strong effect of Hed1 in preventing complex formation between Rad51 and Rad54. Specifically, while nearly all of the Rad51 protein became associated with Rad54 in Hed1's absence, the inclusion of Hedl led to a greatly diminished level of the Rad51-Rad54 complex (Fig. 3A, cf. lanes 3 and 6). We did not observe any direct interaction between Hed1 and Rad54 (data not shown). By affinity pull-down, we found that Dmc1 also binds Rad54 (Supplemental Fig. S2B) with about the same affinity as Rad51 (data not shown). Interestingly, Hed1 has no effect on the Dmc1-Rad54 interaction (Supplemental Fig. S2B). Taken together, the results revealed that Hed1 strongly interferes with the formation of the Rad51-Rad54 complex.

\section{Hed1 ablates functional synergy between Rad51 and Rad54}

Rad54 hydrolyzes ATP when DNA is present and can utilize its DNA translocase activity to supercoil DNA (Petukhova et al. 1998; Tan et al. 2003). The ATPase and DNA supercoiling activities are up-regulated upon complex formation with Rad51 (Mazin et al. 2000a; Van Komen et al. 2000). Consistent with the results from the affinity pull-down experiments (Fig. 3A), Hedl ablated the enhancement of the Rad54 ATPase activity by Rad51 (Fig. 3B); we note that the residual level of ATP hydrolysis at the highest Hed 1 concentration was very similar to the Rad54 alone level. Indeed, even the highest concentration of Hed1 did not affect ATP hydrolysis by Rad54 (Fig. 3B).

The Rad54 DNA supercoiling activity can be conveniently monitored by a topoisomerase-linked assay (Petukhova et al. 1999; Van Komen et al. 2000). Specifically, the negative supercoils generated by Rad54 are removed by Escherichia coli topoisomerase I to yield overwound (OW) DNA (Fig. $3 \mathrm{C}$ ) as the product. In agreement with results from the examination of ATPase activity (Fig. 3B), Hed1 did not inhibit DNA supercoiling by Rad54 alone (Fig. 3E) but strongly suppressed the enhancement of this Rad54 activity by Rad51 (Fig. 3D).

During HR that is triggered by a DSB, the first DNA joint formed between the recombining DNA molecules is the D-loop. It is well established that the Rad51-mediated D-loop reaction is strongly stimulated by Rad54 (Petukhova et al. 1998; Mazin et al. 2000b; Sung et al. 2003). We asked whether Hed1 would interfere with the Rad51/Rad54-mediated D-loop reaction. In this reaction, the Rad51 presynaptic filament assembled on linear radiolabeled ssDNA invades a homologous duplex, and the D-loop product is revealed by the phosphorimaging analysis of agarose gels in which reaction mixtures have been resolved (Fig. 4A). As reported previously (Petukhova et al. 1998; Mazin et al. 2000b), while Rad51 on its own catalyzed D-loop formation poorly ( $\leq 1 \%$ D-loop) (Fig. 4B, lane 2), the addition of Rad54 rendered the reaction robust (Fig. 4B, lane 6). Importantly, the inclusion 
A

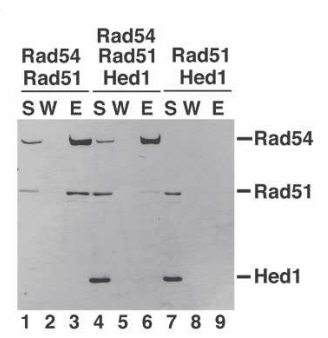

B

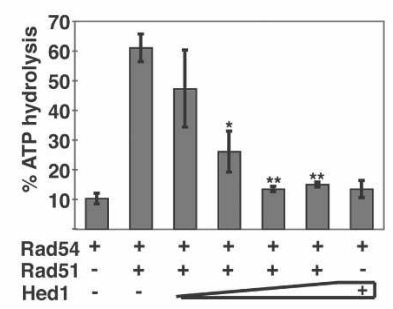

C

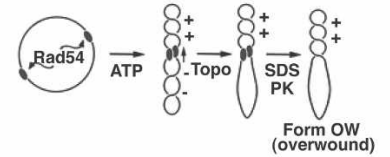

D

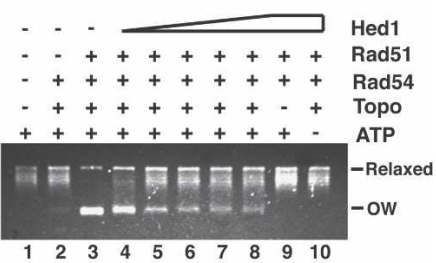

E

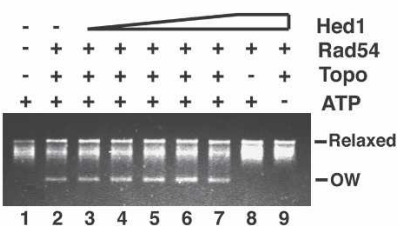

Figure 3. Hed1 prevents Rad51-Rad54 interaction. $(A)$ Rad51 (5 $\mu \mathrm{g}$ ) and S-tagged Rad54 (15 $\mu \mathrm{g})$ were incubated with or without Hed1 $(10 \mu \mathrm{g})$, and protein complexes were captured with S-protein agarose beads. The fractions were analyzed by SDS-PAGE as in Figure 1C. $(B)$ ATP hydrolysis by Rad54 (23 nM) was examined with or without Rad51 (460 nM) and/or Hed1 (133, 532, 266, and $800 \mathrm{nM})$. Error bars represent SEM. $\left({ }^{\star}\right) P \leq 0.05 ;\left(^{\star \star}\right)$ $P \leq 0.001$ compared with Rad51/Rad54-only value. $(C)$ Schematic of the Topoisomerase I (Topo)-linked DNA supercoiling assay (Raschle et al. 2004). (D) DNA supercoiling activity of the Rad51-Rad54 complex was examined with or without Hed1. Rad54 (180 nM) was incubated with or without Rad51 (350 nM), Hed1 (0.3, 0.5, $0.8,1.0$, and $1.25 \mu \mathrm{M})$, and topologically relaxed $\phi \mathrm{X} 174$ RF I DNA (15 $\mu \mathrm{M}$ base pairs). E. coli Topoisomerase I $(100 \mathrm{ng})$ was added after the incubation to relax negative supercoils. (E) DNA supercoiling activity of Rad54 was examined with or without Hed1. Reactions were performed as in $D$ but without Rad51 and with $360 \mathrm{nM}$ Rad54. of Hed1 greatly attenuated the efficiency of the Rad51/ Rad54-mediated D-loop reaction (Fig. 4B, lanes 7-10). Interestingly, in the absence of Rad54, Hed1 slightly enhanced the ability of Rad51 to make D-loops (Fig. 4B, lane 5). We note that Hed1 also had a slight stimulatory effect on Rad51-mediated DNA joint formation using linear ssDNA and dsDNA substrates (Fig. 2C). No Dloop was formed by either Hed1 alone (Fig. 4B, lane 4) or by the combination of Hed1 and Rad54 (data not shown).

Taken together, the above results show clearly that Hed1 ablates the functional synergy between Rad51 and Rad54, which likely stems from Hed1's effect in preventing the assembly of the Rad51-Rad54 complex (Fig. 3A).

\section{Hed 1 prevents the recruitment of Rad54 to a site-specific DSB}

Chromatin immunoprecipitation (ChIP) has been used to examine the targeting of Rad51 and Rad54 to DSBs (Sugawara et al. 2003; Wolner et al. 2003). The results from the published studies have indicated that Rad52 mediates the recruitment of Rad51 to DSBs, while the DSB recruitment of Rad54 is dependent on Rad51 (Sugawara et al. 2003; Wolner et al. 2003). To assess the effect of Hed1 on the DSB recruitment of Rad51 and Rad54, Hed1 protein was expressed in the nonswitching yeast strain JKM179 with the use of the ADH1 promoter (Sugawara et al. 2003). The strain harbors the HO endonuclease gene that is galactose-inducible, which provides a means for the synchronous induction of a DSB at the MAT locus (Fig. 5A; Sugawara et al. 2003). Since the strain lacks the $H M L$ and $H M R$ donor sequences, the resected DNA ends associated with the DSB site at MAT persist for many hours, thus allowing for easy monitoring of accumulation of HR proteins (Moore and Haber 1996; Sugawara et al. 2003; Wolner et al. 2003). The association of Rad51 and myc-tagged Rad54 with the MAT
$Z$ sequence (CEN distal to the $\mathrm{HO}$ cut site at $M A T)$ after the induction of a DSB (Fig. 5A) was assessed by immunoprecipitation with anti-Rad51 or anti-myc antibody (Wolner et al. 2003). Primers for the PHO5 promoter region were included in the ChIP experiments as an internal control (Wolner et al. 2003). Hedl expression had no effect on the kinetics of DSB induction (data not shown). Importantly, Hedl affected neither the timing nor the extent of Rad51 recruitment to the HO-induced break

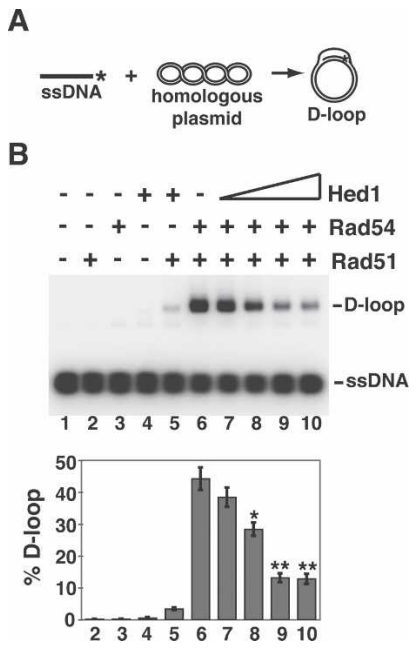

Figure 4. Hed1 Inhibits D-loop formation by Rad51-Rad54 complex. (A) Schematic of the D-loop reaction (Raschle et al. 2004). (B) D-loop formation by Rad51 was examined with or without Rad54 and/or Hed1. Rad51 (1.3 $\mu \mathrm{M})$ was incubated with a radiolabeled single-stranded 90 -mer oligo ( $3 \mu \mathrm{M}$ nucleotides), followed by the addition of Rad54 $(0.4 \mu \mathrm{M})$ and Hed1 $(0.4,0.7$, 1.0 , and $1.3 \mu \mathrm{M})$ as indicated. pBlueScript SK replicative form I DNA (45 $\mu \mathrm{M}$ base pairs) was added to stat the reaction. Error bars represent SEM. $\left(^{\star}\right) P \leq 0.05 ;\left(^{\star \star}\right) P \leq 0.001$ compared with Rad51/Rad54-only value. 
A

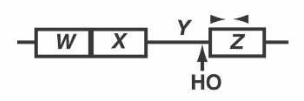

B
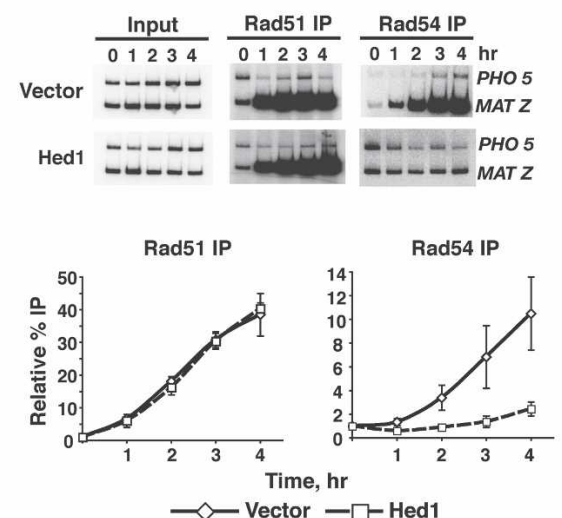

C
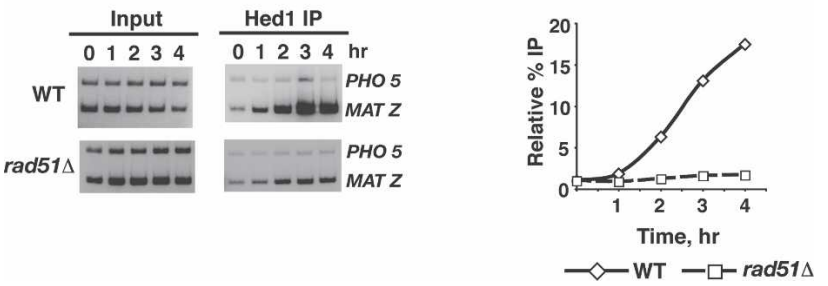

Figure 5. Hed1 interferes with DSB recruitment of Rad54. (A) Schematic representation of MAT locus with the HO endonuclease cut site indicated. Accumulation of recombination proteins at the DSB is monitored by ChIP with primers specific for the MAT $Z$ region (arrowheads). (B) JKM179 cells that express Myc-tagged Rad54 (Wolner et al. 2003) were transformed either with the empty $p T B 326$ vector $(A D H$ promoter) or with pTB326-HED1. The DSB recruitment of Rad51 and Rad54 to $M A T Z$ was evaluated at various times after the induction of an HO break. Input represents $0.1 \%$ of total cell extract volume. The MAT $Z$ signal was quantified as described (Wolner et al. 2003). (C) JKM179 (RAD51) and its rad51D derivative were transformed with pTB326-HED1 that expresses Flag-tagged Hed1. The DSB recruitment of Hed1 was assessed as described in $B$. Error bars represent SEM.

(Fig. 5B). This result indicates that Hed1 has little or no effect on the Rad52-dependent delivery of Rad51 to the HO break and is consistent with our observation that Hed1 does not affect Rad51/Rad52 complex formation (Supplemental Fig. S2). In sharp contrast, in cells that expressed Hed1, little or no Rad54 was recruited to the DSB, even at late time points (Fig. 5B). The ChIP data thus fully validate our biochemical finding of Hed1's ability to prevent the assembly of the $\operatorname{Rad} 51 / \operatorname{Rad} 54$ complex.

In meiotic cells, Hed1 localizes to Spo11-made DSBs in a Rad51-dependent manner (Tsubouchi and Roeder 2006). ChIP was used to query whether Flag-tagged Hed1 is targeted to the HO-made DSB. Immunoprecipitation with anti-Flag antibodies revealed a large enrichment of
Hed1 at the site of HO-induced break in JKM179, but little or no DSB recruitment of Hed1 was seen in isogenic cells deleted for RAD51 (Fig. 5C). Thus, just like in meiotic cells (Tsubouchi and Roeder 2006), Hed1 is targeted to the HO break via Rad51.

\section{Hed1 is less adept at attenuating the Rad51-Rdh54 complex}

The Rdh54 protein is related to Rad54 in primary sequence, and the two proteins possess similar biochemical attributes (Symington 2002; Chi et al. 2006; Nimonkar et al. 2007; Prasad et al. 2007). Like Rad54, Rdh54 enhances the Rad51-mediated D-loop reaction (Petukhova et al. 2000; Symington 2002; Chi et al. 2006). Interestingly, as revealed by affinity pull-down with purified proteins, under the conditions wherein the Rad51Rad54 complex is ablated (Fig. 3A), Hed1 has little effect on Rad51-Rdh54 complex formation (Fig. 6A, cf. lanes 3 and 6). Likewise, we found that Hed1's negative effect on Rad51/Rdh54-mediated D-loop formation is much less pronounced than in the case of the Rad51/Rad54 pair (cf. Figs. 4B and 6B). Finally, with the aid of ChIP, we verified that Rdh54's localization to DSBs (Lisby et al. 2004) is
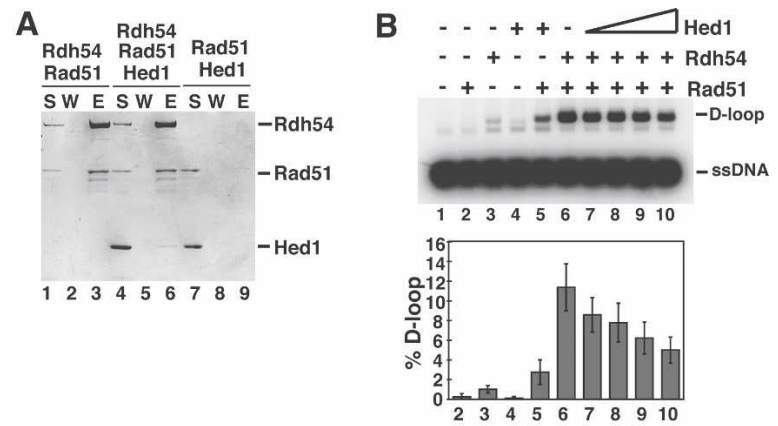

C
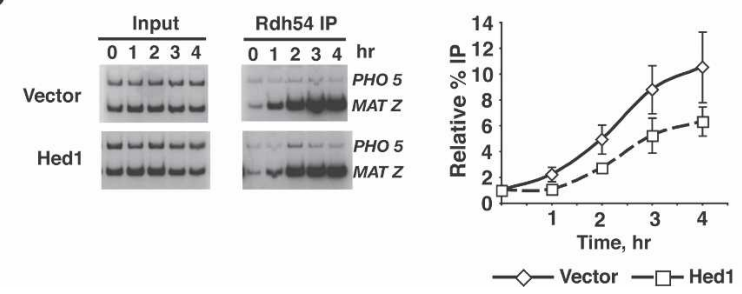

Figure 6. Effects of Hed1 on the Rad51-Rdh54 complex. (A) Purified Rad51 (5 $\mu \mathrm{g})$ and S-tagged Rdh54 (15 $\mu \mathrm{g})$ were incubated with or without Hed1 $(10 \mu \mathrm{g})$, and protein complexes were captured with anti-S-agarose beads. The fractions were analyzed by SDS-PAGE as in Figure 1C. (B) D-loop formation by Rad51 (1.3 $\mu \mathrm{M})$ was examined with or without Rdh54 $(0.4 \mu \mathrm{M})$ and/or Hed1 $(0.4,0.7,1.0$, and $1.3 \mu \mathrm{M})$ as indicated. Reactions were performed as in Figure 4B. $(C)$ Recruitment of Rdh54 to DSBs in the presence of Hed1. JKM179 cells that express Flag-tagged Rdh54 were transformed either with the empty $p$ TB326 vector or with pTB326-HED1. The DSB recruitment of Rdh54 to MAT Z was evaluated at various times after the induction of an HO break. Input represents $0.1 \%$ of total cell extract volume. Error bars represent SEM. 
only slightly affected by Hed1 expression (Fig. 6C). Overall, the results revealed that Hed1 is much less adept at attenuating the formation and functional integrity of the Rad51-Rdh54 complex.

\section{Discussion}

Mechanistic basis for Hed1-dependent recombination regulation

Whereas Rad51 alone is adept at catalyzing efficient recombination in mitotic cells, meiotic recombination shows a strong reliance on Dmc1 as well. The existing evidence suggests that the activity of Rad51 is downregulated in meiosis, so as to ensure that a large enough fraction of the programmed, Spo11-made DSBs are channeled into the Dmc1-dependent recombination pathway, thus creating an interhomolog bias (with regard to recombination partner choice) that is critical for chromosome segregation in meiosis I.

It has been suggested that Red1, Hop1, and Mek1 proteins that are associated with the axial elements suppress Dmcl-independent recombination in an indirect fashion, possibly by influencing the structure of meiotic chromosomes (for review, see Sheridan and Bishop 2006). In contrast, Hed1 appears to regulate meiotic recombination via a direct action on Rad51 (Tsubouchi and Roeder 2006). Thus, deletion of HED1 bypasses the meiotic cell cycle arrest caused by the $d m c 1 \Delta$ mutation and also suppresses the meiotic defects caused by mutating $H O P 2$, which codes for a Dmc1 accessory factor, as the hed1s mutation permits Rad51-mediated repair of meiotic DSBs in Dmc1's or Hop2's absence. Cytological, yeast two-hybrid, and mitotic expression studies have provided support for the premise that Hed1 physically interacts with Rad51 and attenuates the recombination reaction catalyzed by Rad51 alone (Tsubouchi and Roeder 2006).
In this study, by biochemical means and ChIP, we endeavored to understand the mechanistic basis of Hed1's action in the regulation of Rad51-mediated recombination. Specifically, we provided direct evidence that Hed1 interacts avidly with Rad51 but has only a weak affinity for Dmc1, results that are consistent with previous findings from yeast two-hybrid and cytological analyses (Tsubouchi and Roeder 2006). Importantly, we demonstrated that Hed1 strongly interferes with the formation of the Rad51-Rad54 complex but has no effect on the Dmc1-Rad54 complex. As a result of this Hed1 action, the functional synergy of the Rad51-Rad54 protein pair is ablated. Likewise, the expression of Hed1 in mitotic cells prevents the recruitment of Rad54 to DSBs. These negative effects of Hedl are highly specific for the Rad51-Rad54 axis, as Hed1 does not seem to diminish Rad51's ability to interact with Rad52 or Rdh54 protein, nor does it adversely affect the Rad52-dependent loading of Rad51 onto DSBs or the recruitment of Rdh54 to DSBs. With purified proteins, we found that Rad51 interacts with Rdh54 more avidly than with Rad54 (data not shown). This could explain the apparent specificity of Hed1 for the Rad51-Rad54 complex.

We present in Figure 7 a model that highlights the essence of our results bearing on the mechanism of action of Hed1 to explain how this novel factor helps regulate recombination pathway choice during meiosis. Our model posits that Hed1 suppresses intersister recombination events by blocking the physical interaction and functional synergy between Rad51 and Rad54, thereby facilitating Rdh54-dependent interhomolog recombination. However, since $r d h 54$ mutants retain a significant level of spore viability and show normal map distances among viable spores (Shinohara et al. 2003), meiotic interhomolog recombination can also occur via Rad54. Furthermore, since Hed1 does associate with Dmc1, albeit only weakly, it remains possible that Hed1 also
A

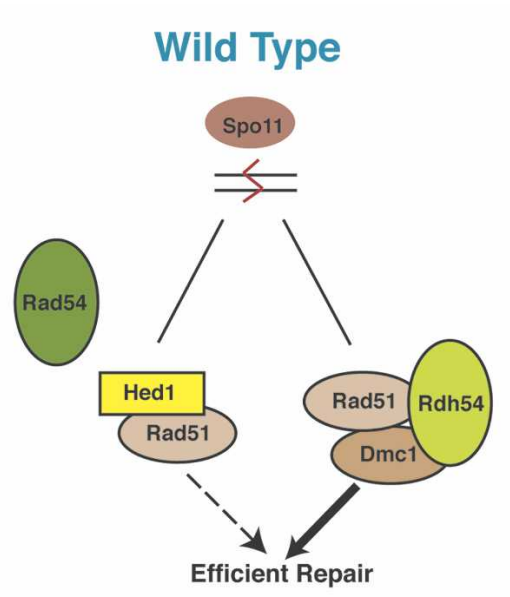

B

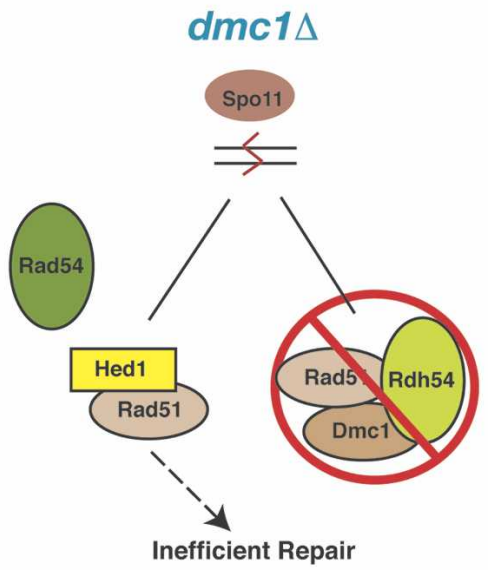

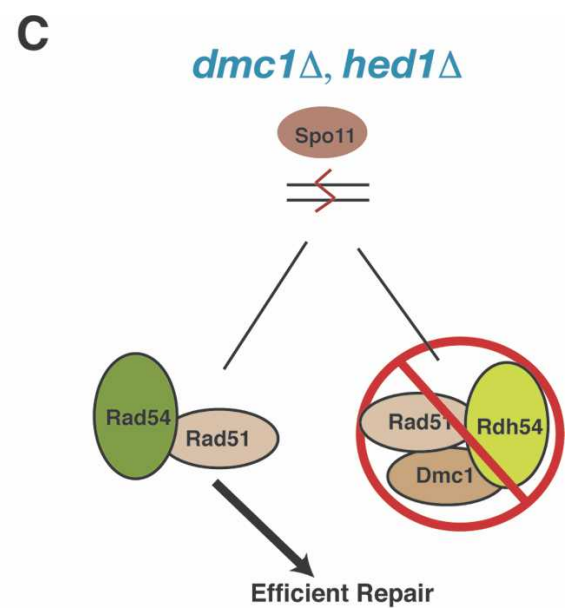

Figure 7. Model for Hed1 action in meiosis. (A) In wild-type cells, Hed1 attenuates the Rad51-only recombination pathway by preventing the assembly of the Rad51-Rad54 complex. The Dmc1/Rad51/Rdh54-dependent pathway is fully operative. (B) Owing to Hed1's action, the repair of DSBs is inefficient in $d m c 1 \Delta$ cells. $(C)$ Deletion of HED1 restores efficient DSB repair by the Rad51-only pathway in $d m c 1 \Delta$ cells. 
regulates Dmc1-mediated HR reactions, especially intersister events.

By a DNA mobility shift assay, we found that Hed1 binds $\phi X 174$ ssDNA but has little affinity for the linear dsDNA form (data not shown). It remains to be established whether ssDNA binding by Hed1 is relevant for its $\mathrm{HR}$ regulatory role.

\section{Other recombination regulatory mechanisms}

In mitotic cells, the recombinational repair of DSBs induced by DNA-damaging agents or that arise from the processing of injured DNA replication forks is mostly directed by the intact sister chromatid. The preference for the sister chromatid as a recombination partner helps ensure the preservation of the genetic configuration of the initiator chromosome during repair (Symington 2002). Moreover, multiple mechanisms exist to prevent the formation of crossovers in mitotic cells, so as to minimize the occurrence of spurious chromosomal rearrangements and the loss of heterozygosity associated with such recombination events. The avoidance of mitotic crossovers is achieved by the choice utilization of the SDSA recombination pathway that generates exclusively noncrossover recombinants (Symington 2002) and also by a noncrossover means of Holliday structure resolution known as double Holliday junction (dHJ) dissolution (Wu and Hickson 2003).

The channeling of DNA lesions into the SDSA pathway of HR is made possible via the action of specialized DNA helicases, including the Srs2 and Sgs1 helicases in $S$. cerevisiae and the BLM helicase in mammalian cells. Srs 2 acts by dismantling the Rad51 presynaptic filament, which likely minimizes the chance of second DNA end capture during DSB repair, a crucial step in crossover formation (Ira et al. 2003; Krejci et al. 2003; Veaute et al. 2003; Sung and Klein 2006). This activity of Srs2 seems to be important for preventing untimely recombination events as well (Symington 2002; Veaute et al. 2003; Sung and Klein 2006). Interestingly, BLM functions in a tripartite fashion, by disrupting the D-loop intermediate (van Brabant et al. 2000; Hickson 2003), by acting in conjunction with Topoisomerase III $\alpha$ to dissolve the $\mathrm{dHJ}(\mathrm{Wu}$ and Hickson 2003; Sung and Klein 2006), and by disrupting the Rad51 presynaptic filament (Bugreev et al. 2007). Sgs1 is orthologous to BLM and, like BLM, associates with Topoisomerase III $\alpha$ (Bennett et al. 2000; Bennett and Wang 2001; Fricke et al. 2001). Based on its structural and functional similarity to BLM, Sgs1 is expected to dissociate the D-loop intermediate, disrupt the Rad51 presynaptic filament, and function with Topoisomerase III $\alpha$. Importantly, the ATPase activity of Srs 2 and BLM is apparently indispensable for their recombination regulatory role (Krejci et al. 2003, 2004; Wu and Hickson 2003; Bussen et al. 2007).

Compared with the aforementioned regulators of recombination, Hed1 acts through a mechanism that is distinct in purpose and molecular details. First, Hed1 facilitates rather than suppresses the formation of crossovers (Tsubouchi and Roeder 2006). Second, Hed1 does not possess any ATPase activity, nor does it disrupt the Rad51 presynaptic filament. Rather, Hed1 provides a structural barrier that limits the interaction of Rad54 with Rad51.

\section{Implications for the role of Rad54 and Rdh54 in mitotic versus meiotic recombination}

Rad54 and Rdh54 are members of the Swi2/Snf2 superfamily. These proteins possess similar biochemical attributes and each can enhance the recombinase activity of Rad51 (Symington 2002). However, results from genetic analyses have shown nonredundant functions of Rad54 and Rdh54 in mitotic and meiotic cells. Specifically, Rad54 plays a more prominent role in intrachromosomal and sister chromatid-based recombination reactions in mitotic cells, whereas allelic (i.e., interhomo$\log$ ) recombination appears to be more reliant on Rdh54 (Klein 1997; Shinohara et al. 1997). Rdh54, but not $\operatorname{Rad} 54$, is also required for cells' adaptation from DNA damage checkpoint-imposed G2/M arrest (Lee et al. 2001; Symington 2002). Interestingly, while Rdh54 is clearly needed for meiotic recombination, Rad54 appears to play only a minor role (Shinohara et al. 1997). The existing evidence suggests that Rdh54 works in the Dmc1-dependent pathway (Shinohara et al. 2003).

Whether or not the lack of a strong dependence of meiotic recombination on Rad54 is related to the interference that Hed1 imposes on the Rad51-Rad54 axis remains to be determined. However, it is interesting to note that overexpression of Rad54 can partially suppress the meiotic deficits of the $d m c 1 \Delta$ mutant (Bishop et al. 1999), consistent with the premise that an elevated level of Rad54 can partially bypass the Hed1 block.

\section{Closing remarks}

Our work with Hed1 has unveiled a new means of recombination regulation; i.e., by restricting access of a key recombinase ancillary factor $(\operatorname{Rad} 54)$ to the presynaptic filament. This novel recombination regulatory mechanism is expected to facilitate meiotic crossover formation between homologs and chromosome disjunction in the first meiotic division (Tsubouchi and Roeder 2006). Almost all eukaryotic species, including humans, harbor Rad51 and Dmc1. It will be important to identify and characterize the Hedl equivalent in other eukaryotes. In this regard, our biochemical and genetic studies with budding yeast Hed1 should constitute a valuable guide.

\section{Materials and methods}

Protein purification

Expression and purification of Hed1 Hed1-(His) ${ }_{6}$ in the vector pET11 (Novagen) or GST-Hed1-(His) ${ }_{6}$ in the vector pGEX-6P1 (Amersham/GE Healthcare) was introduced into BL21:DE3 Rosetta cells (Novagen). Cells were grown at $37^{\circ} \mathrm{C}$ to an $\mathrm{OD}_{600}$ of 
0.8 and induced with $0.1 \mathrm{mM}$ IPTG for $16 \mathrm{~h}$ at $16^{\circ} \mathrm{C}$. Multistep procedures (see the Supplemental Material for details) were developed for the purification of the tagged Hedl proteins to near homogeneity.

Other proteins We used our published procedures for the purification of Rad51 (Sung and Stratton 1996), Rad52 (Song and Sung 2000), Rad54 (Raschle et al. 2004), and Rdh54 (Chi et al. 2006). Both Rad54 and Rdh54 harbor N-terminal (His) ${ }_{6}$ and $S$ affinity tags. The purification procedure for Dmcl will be described elsewhere.

\section{ATPase assays}

Assay for Rad54 ATPase activity Rad54 (23 nM) was incubated with or without Rad51 (460 nM) and Hed1 $(133,266,532$, and $800 \mathrm{nM}$ ) in $10 \mu \mathrm{L}$ of Buffer $\mathrm{D}(50 \mathrm{mM}$ Tris- $\mathrm{HCl}$ at $\mathrm{pH} 7.5,5$ $\mathrm{mM} \mathrm{MgCl} 2,1 \mathrm{mM} \mathrm{DTT}, 100 \mu \mathrm{g} / \mathrm{mL}$ bovine serum albumin) containing $1 \mathrm{mM}$ ATP, $0.5 \mu \mathrm{Ci}\left[\gamma^{-32} \mathrm{P}\right] \mathrm{ATP}$, and $100 \mathrm{mM} \mathrm{KCl}$ for $10 \mathrm{~min}$ on ice. $\phi X 174$ RF I DNA ( $22 \mu \mathrm{M}$ base pairs) was added to initiate the ATP hydrolysis reaction. After $15 \mathrm{~min}$ at $30^{\circ} \mathrm{C}$, EDTA was added to $250 \mathrm{mM}$ to halt the reaction. Thin-layer chromatography and phosphorimaging analysis were used to assess the level of ATP hydrolysis (Petukhova et al. 1998).

Assay for Rad51 ATPase activity The reaction was conducted as described above, with modifications. $\operatorname{Rad} 51(3.45 \mu \mathrm{M})$ was incubated with or without Hed1 $(1.3,2.6,3.7 \mu \mathrm{M})$ in Buffer D with $100 \mu \mathrm{M}$ ATP. $\phi \mathrm{X}$ virion ssDNA (90 $\mu \mathrm{M}$ nucleotides) was added to initiate the ATP hydrolysis reaction, which was allowed to proceed for $40 \mathrm{~min}$ at $37^{\circ} \mathrm{C}$.

\section{Affinity pull-down assays}

For pull-down assays, Rad51 (5 $\mu \mathrm{g})$, S-tagged Rad54 (15 $\mu \mathrm{g})$, Stagged Rdh54 (15 $\mu \mathrm{g})$, GST-tagged Rad52 (10 $\mu \mathrm{g})$, GST-Hed1 (5 $\mu \mathrm{g})$, (His $)_{6}$-tagged Hed1 $(10 \mu \mathrm{g})$, $(\mathrm{His})_{6}$-tagged Dmcl $(5 \mu \mathrm{g}$ in Fig. 1D, lanes 1-6, and Supplemental Fig. S2B; $10 \mu \mathrm{g}$ in Fig. 1D, lanes

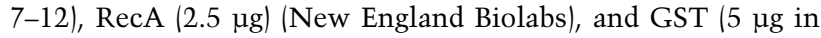
Fig. 1; $10 \mu \mathrm{g}$ in Supplemental Fig. S2) were used. The indicated proteins were incubated in $30 \mu \mathrm{L}$ of Buffer B $(25 \mathrm{mM}$ Tris- $\mathrm{HCl}$ at $\mathrm{pH} 7.5,0.005 \%$ Triton, $200 \mathrm{mM} \mathrm{KCl}, 1 \mathrm{mM} \mathrm{DTT}$ ) for $30 \mathrm{~min}$ at $4^{\circ} \mathrm{C}$. The reactions were mixed with $11 \mu \mathrm{L}$ of S-protein agarose beads (which recognize the $\mathrm{S}$ tag at the $\mathrm{N}$ terminus of Rad54 and Rdh54) (Novagen) or glutathione-Sepharose beads (which bind GST) (Amersham Biosciences) for $30 \mathrm{~min}$ at $4^{\circ} \mathrm{C}$. After washing the beads twice with $200 \mu \mathrm{L}$ of the same buffer, bound proteins were eluted with $25 \mu \mathrm{L}$ of $2 \%$ SDS. Fifteen percent of total supernatant (S) and elution (E) fractions, and $2 \%$ of total wash (W) fraction were analyzed by $10 \%$ SDS-PAGE and Coomassie Blue staining.

\section{Oligonucleotide-based homologous DNA pairing assay}

The assay was performed as described previously (San Filippo et al. 2006). Briefly, $\operatorname{Rad} 51(3.45 \mu \mathrm{M})$ or $\operatorname{Rec} A(3.9 \mu \mathrm{M})$ was incubated with 150-mer ssDNA oligonucleotide (6 $\mu \mathrm{M}$ nucleotides) in $9 \mu \mathrm{L}$ of Buffer D containing $2.5 \mathrm{mM}$ ATP and $30 \mathrm{mM} \mathrm{KCl}$ for $5 \mathrm{~min}$ at $37^{\circ} \mathrm{C}$. Subsequently, Hed $1(0.5,1.3,2.6,3.7$, or $4.3 \mu \mathrm{M})$ was added in $0.5 \mu \mathrm{L}$, followed by the addition of $1 \mu \mathrm{L}$ of $50 \mathrm{mM}$ spermidine and ${ }^{32} \mathrm{P}$-labeled homologous 40-mer dsDNA $/ 6 \mu \mathrm{M}$ base pairs) in $0.5 \mu \mathrm{L}$. The reaction mixtures were incubated for $30 \mathrm{~min}$ at $37^{\circ} \mathrm{C}$ and then stopped by the addition of an equal volume of $1 \%$ SDS containing $1 \mathrm{mg} / \mathrm{mL}$ proteinase $\mathrm{K}$. After a 3-min incubation at $37^{\circ} \mathrm{C}$, the deproteinized samples were subjected to electrophoresis in $10 \%$ polyacrylamide gels at $4^{\circ} \mathrm{C}$ in
TAE buffer (40 mM Tris acetate at $\mathrm{pH} 7.4,0.5 \mathrm{mM}$ EDTA). The gels were dried and analyzed in the PhosphorImager.

\section{D-loop assay}

The D-loop reaction was performed as described previously (Raschle et al. 2004). Briefly, Rad51 (1.3 $\mu \mathrm{M})$ was incubated with ${ }^{32}$ P-labeled 90-mer oligonucleotide substrate ( $3 \mu \mathrm{M}$ nucleotides) in $11 \mu \mathrm{L}$ of Buffer D containing $4 \mathrm{mM} \mathrm{ATP}$ and an ATP-regenerating system $(20 \mathrm{mM}$ creatine phosphatase, $30 \mu \mathrm{g} / \mathrm{mL}$ creatine kinase) and $30 \mathrm{mM} \mathrm{KCl}$ for $5 \mathrm{~min}$ at $37^{\circ} \mathrm{C}$. $\operatorname{Rad} 54(0.4 \mu \mathrm{M})$ and Hed1 $(0.4,0.7,1.0$, and $1.3 \mu \mathrm{M})$ were each added in $0.5 \mu \mathrm{L}$, followed by a 5 -min incubation at $25^{\circ} \mathrm{C}$. The D-loop reaction was initiated by the addition of pBlueScript SK replicative form I DNA ( $45 \mu \mathrm{M}$ base pairs) in $1 \mu \mathrm{L}$. The reactions were incubated for $6 \mathrm{~min}$ at $30^{\circ} \mathrm{C}$ and stopped by the addition of SDS and proteinase $\mathrm{K}$, as above. The deproteinized samples were subject to electrophoresis in $0.9 \%$ agarose gels and analyzed as above.

\section{Topoisomerase I-linked DNA supercoiling assay}

Reactions were performed as described previously (Van Komen et al. 2000; Raschle et al. 2004). Briefly, Rad54 (180 nMin Fig. 3E; $360 \mathrm{nM}$ in Fig. 3D) was incubated with or without Rad51 $(350 \mathrm{nM})$ and Hed1 $(0.3,0.5,0.8,1.0$, and $1.25 \mu \mathrm{M})$ in $9 \mu \mathrm{L}$ of Buffer D containing $2.5 \mathrm{mM}$ ATP, $50 \mathrm{mM} \mathrm{KCl}$, and an ATPregenerating system $(10 \mathrm{mM}$ creatine phosphatase, $28 \mu \mathrm{g} / \mathrm{mL}$ creatine kinase) for $10 \mathrm{~min}$ on ice. Topologically relaxed $\phi \mathrm{X} 174$ RF I DNA (15 $\mu$ M base pairs) was then added in $0.5 \mu \mathrm{L}$, followed by a 5 -min incubation at $30^{\circ} \mathrm{C}$. E. coli Topoisomerase I (100 ng) was then added in $0.5 \mu \mathrm{L}$ to complete the reactions, which were incubated for $10 \mathrm{~min}$ at $30^{\circ} \mathrm{C}$. The reactions were processed by agarose gel electrophoresis. The DNA species were visualized by staining with ethidium bromide.

\section{ChIP}

JKM179 strain (ho hml::ADE1 MAT $h m r:: A D E 1$ ade1-110 leu2,3-112 lys5 trp1::hisG ura3-52 ade3::GAL10:HO) (Moore and Haber 1996; Sugawara et al. 2003) with C-terminally 13 myc-tagged RAD54 (Wolner et al. 2003) or C-terminally Flagtagged RDH54 was transformed with $p T B 326(2 \mu A D H 1, T R P 1)$ or pTB326 containing HED1 cDNA (pTB326-HED1). The expression of Hed1 was verified by Western blot with polyclonal antibodies raised against purified $(\mathrm{His})_{6}$-tagged Hed1. For analysis of DSB recruitment of Hed1, JKM179 and its rad51D derivative were transformed with pTB326 or pTB326 containing the HED1 cDNA that harbors an N-terminal Flag tag. Cells were grown in $120 \mathrm{~mL}$ of complete synthetic medium without tryptophan for $36 \mathrm{~h}$ at $30^{\circ} \mathrm{C}$, pelleted, washed twice in $\mathrm{YP}+3 \%$ glycerol medium, resuspended in YP $+3 \%$ glycerol to $\mathrm{OD}_{660}=0.6$ (200 mL total volume), and incubated for $4 \mathrm{~h}$ at $30^{\circ} \mathrm{C}$ before galactose was added to $2 \%$ to induce the expression of the $\mathrm{HO}$ endonuclease. An aliquot of $45 \mathrm{~mL}$ was taken at the indicated time points, and the cells were processed for ChIP as described previously (Sugawara et al. 2003). Immunoprecipitation was with anti-myc antibody (Santa Cruz Biotechnology), anti-Rad51 antibody (Sugawara et al. 2003; Wolner et al. 2003), or anti-Flag agarose (Sigma). The kinetics of DSB formation, and association of the various proteins with the MAT $Z$ and PHO5 sequences, were analyzed by radioactive PCR, as described (Wolner et al. 2003).

\section{Acknowledgments}

We are grateful to Peter Chi for providing Dmcl protein and Changhyun Seong for the JKM179 RDH54-Flag strain. This 
study was supported by the Howard Hughes Medical Institute (S.R. and H.T.), by research grants and a post-doctoral training grant from the US National Institutes of Health (to S.R., P.S., and V.B.), and by a fellowship from the Agency for Science, Technology, and Research, Singapore (I.S.).

\section{References}

Bennett, R.J. and Wang, J.C. 2001. Association of yeast DNA topoisomerase III and Sgs1 DNA helicase: Studies of fusion proteins. Proc. Natl. Acad. Sci. 98: 11108-11113.

Bennett, R.J., Noirot-Gros, M.F., and Wang, J.C. 2000. Interaction between yeast sgs 1 helicase and DNA topoisomerase III. J. Biol. Chem. 275: 26898-26905.

Bishop, D.K., Nikolski, Y., Oshiro, J., Chon, J., Shinohara, M., and Chen, X. 1999. High copy number suppression of the meiotic arrest caused by a dmc1 mutation: REC114 imposes an early recombination block and RAD54 promotes a DMC1-independent DSB repair pathway. Genes Cells 4: 425-444.

Bugreev, D.V., Yu, X., Egelman, E.H., and Mazin, A.V. 2007. Novel pro- and anti-recombination activities of the Bloom's syndrome helicase. Genes \& Dev. 21: 3085-3094.

Bussen, W., Raynard, S., Busygina, V., Singh, A.K., and Sung, P. 2007. Holliday junction processing activity of the BLM-Topo III $\alpha$-BLAP75 complex. J. Biol. Chem. 282: 31484-31492.

Chi, P., Kwon, Y., Seong, C., Epshtein, A., Lam, I., Sung, P., and Klein, H.L. 2006. Yeast recombination factor Rdh54 functionally interacts with the Rad51 recombinase and catalyzes Rad51 removal from DNA. J. Biol. Chem. 281: 26268-26279.

Fricke, W.M., Kaliraman, V., and Brill, S.J. 2001. Mapping the DNA topoisomerase III binding domain of the Sgs1 DNA helicase. J. Biol. Chem. 276: 8848-8855.

Heyer, W.D., Li, X., Rolfsmeier, M., and Zhang, X.P. 2006. Rad54: The Swiss Army knife of homologous recombination? Nucleic Acids Res. 34: 4115-4125.

Hickson, I.D. 2003. RecQ helicases: Caretakers of the genome. Nat. Rev. Cancer 3: 169-178.

Ira, G., Malkova, A., Liberi, G., Foiani, M., and Haber, J.E. 2003. Srs2 and Sgs1-Top3 suppress crossovers during doublestrand break repair in yeast. Cell 115: 401-411.

Keeney, S., Giroux, C.N., and Kleckner, N. 1997. Meiosis-specific DNA double-strand breaks are catalyzed by Spo11, a member of a widely conserved protein family. Cell 88: 375 384.

Klein, H.L. 1997. RDH54, a RAD54 homologue in Saccharomyces cerevisiae, is required for mitotic diploid-specific recombination and repair and for meiosis. Genetics 147: 15331543.

Krejci, L., Song, B., Bussen, W., Rothstein, R., Mortensen, U.H., and Sung, P. 2002. Interaction with Rad51 is indispensable for recombination mediator function of Rad52. I. Biol. Chem. 277: 40132-40141.

Krejci, L., Van Komen, S., Li, Y., Villemain, J., Reddy, M.S., Klein, H., Ellenberger, T., and Sung, P. 2003. DNA helicase Srs2 disrupts the Rad51 presynaptic filament. Nature 423: 305-309.

Krejci, L., Macris, M., Li, Y., Van Komen, S., Villemain, J., Ellenberger, T., Klein, H., and Sung, P. 2004. Role of ATP hydrolysis in the antirecombinase function of Saccharomyces cerevisiae Srs2 protein. J. Biol. Chem. 279: 23193-23199.

Lee, S.E., Pellicioli, A., Malkova, A., Foiani, M., and Haber, J.E. 2001. The Saccharomyces recombination protein Tidlp is required for adaptation from $\mathrm{G} 2 / \mathrm{M}$ arrest induced by a double-strand break. Curr. Biol. 11: 1053-1057.
Lisby, M., Barlow, J.H., Burgess, R.C., and Rothstein, R. 2004. Choreography of the DNA damage response: Spatiotemporal relationships among checkpoint and repair proteins. Cell 118: 699-713.

Mazin, A.V., Bornarth, C.J., Solinger, J.A., Heyer, W.D., and Kowalczykowski, S.C. 2000a. Rad54 protein is targeted to pairing loci by the Rad51 nucleoprotein filament. Mol. Cell 6: $583-592$.

Mazin, A.V., Zaitseva, E., Sung, P., and Kowalczykowski, S.C. 2000b. Tailed duplex DNA is the preferred substrate for Rad51 protein-mediated homologous pairing. EMBO J. 19: $1148-1156$.

Moore, J.K. and Haber, J.E. 1996. Capture of retrotransposon DNA at the sites of chromosomal double-strand breaks. $\mathrm{Na}$ ture 383: 644-646.

Neale, M.J. and Keeney, S. 2006. Clarifying the mechanics of DNA strand exchange in meiotic recombination. Nature 442: $153-158$.

Nimonkar, A.V., Amitani, I., Baskin, R.J., and Kowalczykowski, S.C. 2007. Single molecule imaging of Tid1/Rdh54, a Rad54 homolog that translocates on duplex DNA and can disrupt joint molecules. J. Biol. Chem. 282: 30776-30784.

Niu, H., Wan, L., Baumgartner, B., Schaefer, D., Loidl, J., and Hollingsworth, N.M. 2005. Partner choice during meiosis is regulated by Hop1-promoted dimerization of Mek1. Mol. Biol. Cell 16: 5804-5818.

Petukhova, G., Stratton, S., and Sung, P. 1998. Catalysis of homologous DNA pairing by yeast Rad51 and Rad54 proteins. Nature 393: 91-94.

Petukhova, G., Van Komen, S., Vergano, S., Klein, H., and Sung, P. 1999. Yeast Rad54 promotes Rad51-dependent homologous DNA pairing via ATP hydrolysis-driven change in DNA double helix conformation. J. Biol. Chem. 274: 2945329462 .

Petukhova, G., Sung, P., and Klein, H. 2000. Promotion of Rad51-dependent D-loop formation by yeast recombination factor Rdh54/Tid1. Genes \& Dev. 14: 2206-2215.

Prasad, T.K., Robertson, R.B., Visnapuu, M.L., Chi, P., Sung, P., and Greene, E.C. 2007. A DNA-translocating Snf2 molecular motor: Saccharomyces cerevisiae Rdh54 displays processive translocation and extrudes DNA loops. J. Mol. Biol. 369: 940-953.

Raschle, M., Van Komen, S., Chi, P., Ellenberger, T., and Sung, P. 2004. Multiple interactions with the Rad51 recombinase govern the homologous recombination function of Rad54. J. Biol. Chem. 279: 51973-51980.

San Filippo, J., Chi, P., Sehorn, M.G., Etchin, J., Krejci, L., and Sung, P. 2006. Recombination mediator and Rad51 targeting activities of a human BRCA2 polypeptide. J. Biol. Chem. 281: 11649-11657.

Schwacha, A. and Kleckner, N. 1997. Interhomolog bias during meiotic recombination: Meiotic functions promote a highly differentiated interhomolog-only pathway. Cell 90: 11231135.

Sheridan, S. and Bishop, D.K. 2006. Red-Hed regulation: Recombinase Rad51, though capable of playing the leading role, may be relegated to supporting Dmcl in budding yeast meiosis. Genes \& Dev. 20: 1685-1691.

Shinohara, A. and Ogawa, T. 1998. Stimulation by Rad52 of yeast Rad51-mediated recombination. Nature 391: 404407.

Shinohara, M., Shita-Yamaguchi, E., Buerstedde, J.M., Shinagawa, H., Ogawa, H., and Shinohara, A. 1997. Characterization of the roles of the Saccharomyces cerevisiae RAD54 gene and a homologue of RAD54, RDH54/TID1, in mitosis and meiosis. Genetics 147: 1545-1556. 
Shinohara, M., Sakai, K., Shinohara, A., and Bishop, D.K. 2003. Crossover interference in Saccharomyces cerevisiae requires a TID1/RDH54- and DMC1-dependent pathway. Genetics 163: 1273-1286.

Song, B. and Sung, P. 2000. Functional interactions among yeast Rad51 recombinase, Rad52 mediator, and replication protein A in DNA strand exchange. J. Biol. Chem. 275: 1589515904.

Sugawara, N., Wang, X., and Haber, J.E. 2003. In vivo roles of Rad52, Rad54, and Rad55 proteins in Rad51-mediated recombination. Mol. Cell 12: 209-219.

Sung, P. 1994. Catalysis of ATP-dependent homologous DNA pairing and strand exchange by yeast RAD51 protein. Science 265: 1241-1243.

Sung, P. and Klein, H. 2006. Mechanism of homologous recombination: Mediators and helicases take on regulatory functions. Nat. Rev. Mol. Cell Biol. 7: 739-750.

Sung, P. and Stratton, S.A. 1996. Yeast Rad51 recombinase mediates polar DNA strand exchange in the absence of ATP hydrolysis. J. Biol. Chem. 271: 27983-27986.

Sung, P., Krejci, L., Van Komen, S., and Sehorn, M.G. 2003. Rad51 recombinase and recombination mediators. J. Biol. Chem. 278: 42729-42732.

Symington, L.S. 2002. Role of RAD52 epistasis group genes in homologous recombination and double-strand break repair. Microbiol. Mol. Biol. Rev. 66: 630-670.

Tan, T.L., Kanaar, R., and Wyman, C. 2003. Rad54, a Jack of all trades in homologous recombination. DNA Repair (Amst.) 2: 787-794.

Tsubouchi, H. and Roeder, G.S. 2003. The importance of genetic recombination for fidelity of chromosome pairing in meiosis. Dev. Cell 5: 915-925.

Tsubouchi, H. and Roeder, G.S. 2006. Budding yeast Hed1 down-regulates the mitotic recombination machinery when meiotic recombination is impaired. Genes \& Dev. 20: 17661775.

van Brabant, A.J., Ye, T., Sanz, M., German, I.J., Ellis, N.A., and Holloman, W.K. 2000. Binding and melting of D-loops by the Bloom syndrome helicase. Biochemistry 39: 14617-14625.

Van Komen, S., Petukhova, G., Sigurdsson, S., Stratton, S., and Sung, P. 2000. Superhelicity-driven homologous DNA pairing by yeast recombination factors Rad51 and Rad54. Mol. Cell 6: 563-572.

Veaute, X., Jeusset, J., Soustelle, C., Kowalczykowski, S.C., Le Cam, E., and Fabre, F. 2003. The Srs2 helicase prevents recombination by disrupting Rad51 nucleoprotein filaments. Nature 423: 309-312.

Wolner, B., van Komen, S., Sung, P., and Peterson, C.L. 2003. Recruitment of the recombinational repair machinery to a DNA double-strand break in yeast. Mol. Cell 12: 221-232.

Wu, L. and Hickson, I.D. 2003. The Bloom's syndrome helicase suppresses crossing over during homologous recombination. Nature 426: 870-874.

$\mathrm{Xu}$, L., Weiner, B.M., and Kleckner, N. 1997. Meiotic cells monitor the status of the interhomolog recombination complex. Genes \& Dev. 11: 106-118. 


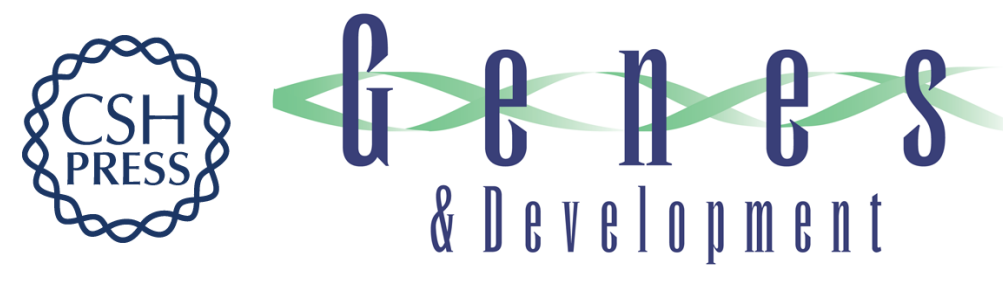

\section{Hed1 regulates Rad51-mediated recombination via a novel mechanism}

Valeria Busygina, Michael G. Sehorn, Idina Y. Shi, et al.

Genes Dev. 2008, 22:

Access the most recent version at doi:10.1101/gad.1638708

Supplemental

http://genesdev.cshlp.org/content/suppl/2008/03/03/22.6.786.DC1

Material

References This article cites 50 articles, 26 of which can be accessed free at: http://genesdev.cshlp.org/content/22/6/786.full.html\#ref-list-1

License

Email Alerting Receive free email alerts when new articles cite this article - sign up in the box at the top Service right corner of the article or click here.

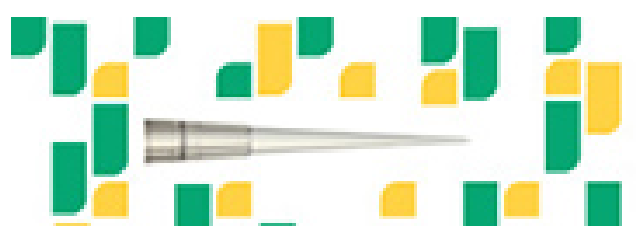

Focused on your science. 